\title{
Moderators of the effectiveness of an intervention to increase colorectal cancer screening through mailed fecal immunochemical test kits: results from a pragmatic randomized trial
}

\author{
Elizabeth A. O'Connor ${ }^{* *}$ (D, William M. Vollmer ${ }^{1}$, Amanda F. Petrik', Beverly B. Green ${ }^{2}$ and Gloria D. Coronado ${ }^{1}$
}

\begin{abstract}
Background: Colorectal cancer (CRC) screening rates remain suboptimal, particularly in low-income and underserved populations. Mailed fecal immunochemical testing (FIT) may overcome common barriers to screening; however, the effect of mailed FIT kits may differ across important subpopulations. The goal of the current study was to examine sociodemographic and health-related factors that moderate the effect of an intervention of automated direct mail of FIT kits at health clinics serving low-income populations.

Methods: This study is a secondary analysis of the Strategies and Opportunities to Stop Colon Cancer in Priority Populations (STOP CRC) study, a cluster-randomized pragmatic trial to increase uptake of CRC screening in patients seen at federally qualified health centers. The intervention involved tools embedded in the electronic medical records to enable participating clinics to mail FIT kits and related materials to eligible participants. We examined the rate of FIT completion by potential moderating characteristics using electronic health record data supplemented by the American Community Survey and the Centers for Medicare \& Medicaid Services Geographic Variation datasets, linked via geocoding to patients' addresses. All patients aged 50-75 seen in participating health clinics who were eligible for CRC screening were included.
\end{abstract}

Results: Although not always statistically significant, we saw a consistent pattern of increased FIT return rates among intervention participants compared to control participants across all subgroups studied, with incidence rate ratios (IRRs) generally ranging from 1.25 to 1.50 . FIT completion in the intervention group ranged from 15 and $20 \%$ across subpopulations, typically three to six percentage points higher than the control group participants. The only moderator with a statistically significant interaction was race: persons of Asian descent showed a twofold response to the intervention (adjusted incidence rate ratio [alRR] $=2.06,95 \%$ confidence interval 1.41 to 3.00 ).

Conclusions: Response to a mailed FIT intervention was generally consistent across a wide range of individual and neighborhood-level patient characteristics, including typically underserved patients and those in low-resource communities.

Trial registration: ClinicalTrials.gov, NCT01742065. Registered on 5 December 2012.

Keywords: Colorectal cancer, Prevention, Screening, Fecal immunochemical test, Disparities

\footnotetext{
* Correspondence: Elizabeth.OConnor@kpchr.org

${ }^{1}$ Kaiser Permanente Center for Health Research, 3800 N. Interstate Avenue,

Portland, OR 97227, USA

Full list of author information is available at the end of the article
}

(c) The Author(s). 2020 Open Access This article is distributed under the terms of the Creative Commons Attribution 4.0 International License (http://creativecommons.org/licenses/by/4.0/), which permits unrestricted use, distribution, and reproduction in any medium, provided you give appropriate credit to the original author(s) and the source, provide a link to the Creative Commons license, and indicate if changes were made. The Creative Commons Public Domain Dedication waiver (http://creativecommons.org/publicdomain/zero/1.0/) applies to the data made available in this article, unless otherwise stated. 


\section{Background}

Colorectal cancer (CRC) is one of the leading causes of cancer mortality $[1,2]$. The US Preventive Services Task Force (USPSTF) gives CRC screening an A-level recommendation for adults aged 50 to 75 [3], and this service is among the highest rated clinical preventive services in the USPSTF's portfolio for its potential to avoid morbidity and mortality and also save costs [4]. A microsimulation model estimated that annual fecal immunochemical testing (FIT) among adults aged 50 to 75 would result in 244 life-years gained per 1000 persons, and other CRC screening methods (e.g., periodic sigmoidoscopy and colonoscopy) showed similar levels of benefit [5]. Despite this, CRC screening is well below targets set by both Healthy People 2020 [6] and the National Colorectal Cancer Roundtable [7].

In addition, there are disparities in CRC screening rates. According to the National Health Interview Survey, CRC screening rates are lower for those with low income, lack of health insurance, low education levels, who lack a source of regular medical care, or who are recent immigrants [8]. Rates are also lower in several race/ ethnicity subgroups, including patients who are Hispanic, Native Hawaiian or other Pacific Islander, and American Indian/Alaska Native [9]. CRC screening is also associated with a number of health-related factors, such as the presence of medical conditions [10-13] and utilization of other preventive health services $[10,12]$.

CRC screening is typically initiated at a medical visit, but there are important known barriers to this approach, such as cost, lack of health insurance, and difficulty attending medical appointments. A mail-based intervention may boost CRC screening rates and reduce disparities in underserved populations by reducing these barriers. A number of studies have shown that mailing FIT kits directly to patients can substantially increase screening rates in low-income, minority, and racially diverse settings [1420]. Screening rates were variable in these studies, ranging from 2 to $37 \%$ at baseline, and with the introduction of a FIT kit, mailing program rates increased by a factor of two to six, with absolute changes typically ranging from 21 to 29 percentage points. Two trials found that mailing FIT kits to patients who were unscreened was more effective in increasing CRC screening than phoning people to schedule colonoscopy appointments after 1 year [16, 20], although this effect did not hold up with a 3-year followup $[21,22]$. Further, a recent study in a health maintenance organization (HMO) setting demonstrated that, among patients who had completed one FIT, 75-86\% completed two additional rounds of screening within 4 years, suggesting good acceptability of this screening method among those who had used it [23]. Similarly, in a study of veterans who had completed a FIT, $89 \%$ found it easy to use and convenient, and $97 \%$ reported that they were likely to complete a FIT by mail annually [24]. In this group of veterans, $79 \%$ completed a second annual FIT test by mail [24].

Understanding whether mailed FIT interventions are broadly effective could assure health systems administrators that this approach would benefit a wide swath of patients and be unlikely to exacerbate or introduce disparities. This study explores whether sociodemographic and health-related factors moderate the effect of an automated direct mail of FIT kit program delivered to patients receiving care at health clinics serving primarily low-income populations.

\section{Materials and methods}

This study is a secondary analysis of data from the Strategies and Opportunities to Stop Colon Cancer in Priority Populations (STOP CRC) study, a clusterrandomized pragmatic trial to increase uptake of CRC screening [25]. The study was approved by the Institutional Review Board of Kaiser Permanente Northwest (Protocol \# 4364), with ceding agreements from Group Health Research Institute and OCHIN (formerly Oregon Community Health Information Network), and is registered at ClinicalTrials.gov (NCT01742065).

\section{Study design and randomization}

The design of the parent trial is described elsewhere in detail $[25,26]$ and is only summarized here. Primary attention here is focused on methods unique to this secondary analysis. Twenty-six clinics from eight federally qualified health centers serving low-income populations were randomized in a one-to-one ratio using a computer-generated randomization strategy prepared by a statistician. Neither clinic staff nor research staff had access to the allocation schedule prior to randomization. Allocation assignments were stratified by health center and blocked to assure maximum balance within health centers. Clinics were required to have a minimum of 450 patients aged $50-75$ years as well as the necessary clinical and laboratory capacity and electronic health record (EHR) infrastructure to comply with the study's requirements. Randomization occurred in February 2014. Due to startup delays trigged by a scheduled upgrade to the EHR, clinics were unable to begin intervention activities until May 2014. As a result, we developed a secondary, lagged dataset that effectively did not begin recruiting intervention or control participants until May 2014 [27]. Sensitivity analyses using this lagged dataset were conducted for the cohort overall to provide what we believe is a more accurate estimate of the true intervention effect [25]. For similar reasons, and to maximize power to observe subgroup and interaction effects, it is this cohort that was used for the present analysis as well (Fig. 1). 


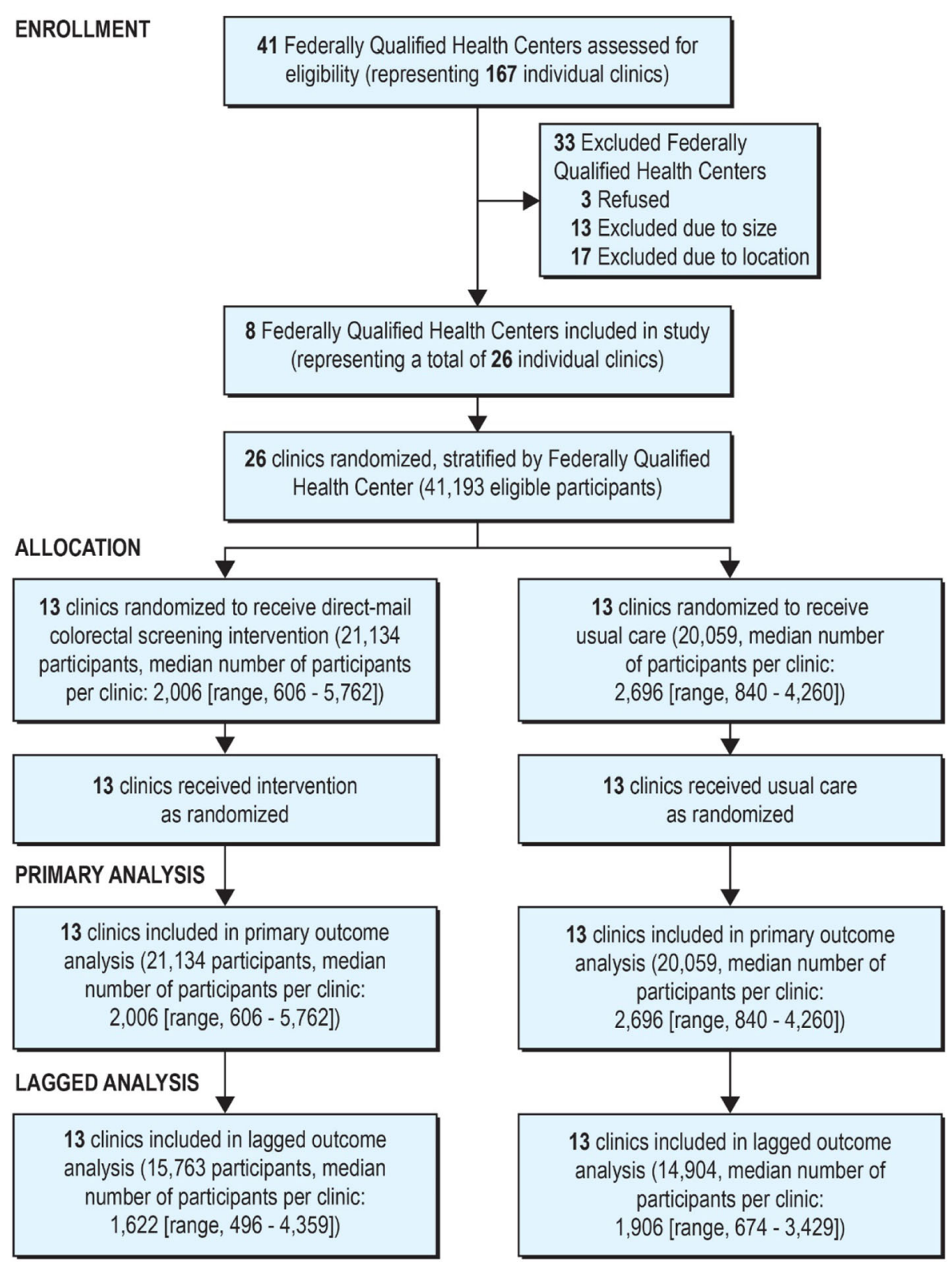

Fig. 1 CONSORT Flowchart of the STOP CRC study

\section{Participants}

Patients from both intervention and control clinics were included in the primary analysis sample if, at any time during the first 12 months post randomization, they were aged 50-75 years, did not already have CRC or other exclusionary diagnoses for CRC screening, and were not compliant with current USPSTF guidelines for screening [3]. The date this occurred defined the starting point for follow-up assessment for each individual.

\section{Intervention}

Tools were developed to enable clinics to use the EHR to generate mailing lists and materials for a series of three mailings: (1) an introductory letter, (2) a FIT kit with a specially designed instructional insert appropriate for use in low-literacy and non-English-speaking populations, and (3) a reminder postcard. Clinics used their own staff to access tools that had been developed collaboratively by clinic administrators, researchers, and the EHR provider and were embedded in the EHR. Staff used these tools to print materials and assemble mailings periodically (typically monthly or quarterly, but the timing of the mailings was determined by the clinics). Research staff provided additional implementation support by facilitating Plan-Do-Study-Act cycles carried out by staff at each health center. 


\section{Main measures \\ Outcome}

The primary outcome for this analysis was completion of a FIT, as identified through EHR laboratory data, after becoming eligible for the intervention. As noted elsewhere, we defined the follow-up interval for outcome assessment for each individual as the earlier of 12 months post initial accrual or August 2015, when intervention activities were initiated in the control clinics [25, 27]. Follow-up windows therefore ranged from 6 to 12 months but were comparably distributed for intervention and control participants.

All participants in the lagged dataset were included in this analysis; those with no evidence of having a returned FIT in their medical record were counted as not completing a FIT. We did not attempt to identify or remove patients who had moved away from the area or had moved their care to another health system.

\section{Moderators}

We primarily explored moderators related to socioeconomic status, healthcare access, language (as a proxy for recency of immigration), and demographics such as race/ethnicity, which are known to be associated with screening rate disparities. In addition, we explored individual characteristics, identified from the EHR and related administrative data, including age, gender, race, Hispanic ancestry, primary language, federal poverty level category, insurance status, body mass index (BMI), smoking status, whether the participant had a flu shot in the year prior to randomization, whether the participant was current on Pap test and mammography screening (females only), number of Charlson comorbidities [28], and whether they had a visit for diabetes, depression, or a chronic pulmonary condition in the year prior to their enrollment date. The last values entered in the EHR prior to each person's enrollment date were used for employment status, poverty level, insurance status, and BMI. Neighborhood characteristics were defined based on the participant's address at the time of enrollment, which was linked via geocoding to variables from the American Community Survey census data [29] and the Centers for Medicare \& Medicaid (CMS) Geographic Variation database [30]. These characteristics included emergency department (ED) visits per 1000 CMS enrollees, Generalized Gini Inequality Index [31], median household income, percentage of college graduates, population density, percentage of residents who are at or below the poverty level, and unemployment rate. These neighborhood-level variables were dichotomized based on associated figures in the USA, as close to the year 2014 as possible (for consistency with the timeline of the study). Exact cut-points are shown in Table 1. Dichotomized outcomes were used to enhance interpretability of the findings, although sensitivity analyses were also conducted using the original, continuous measures to ensure dichotomizing the outcomes did not substantially affect the results.

\section{Statistical analysis Primary analysis}

The analytic methods used here are a direct extension of the primary outcome analysis used in the main outcomes paper [25], with the addition of the relevant subgroup variable main effect and treatment interaction terms to permit subgroup-specific treatment estimates and formal estimates of subgroup by treatment interaction. In addition, we used a Poisson rather than logistic link function for the generalized estimating equation (GEE) models and weighted all patients equally to reflect our focus on patient rather than clinic-level effects for this analysis. Finally, we summarized the treatment effects as risk ratios (RRs) rather than as absolute differences or odds ratios for improved comparison with other trials and ease of interpretability. The GEE models used robust variance estimators and specified clinic as a clustering variable to account for intra-clinic correlation. The analysis was conducted in 2017 and 2018.

\section{Results}

We included 30,667 individuals from 26 clinics who were aged 50-74 and were not current on CRC screening. The intervention and usual care groups showed very similar distributions on baseline characteristics, generally within one to four percentage points of each other (Table 2).

Most of the persons in the sample were aged 50-64 (81.5\%), White (88.6\%), and non-Hispanic (86.4\%), and more than half were female $(55.4 \%)$. Most of the participants had household incomes that were below 200\% of the federal poverty level (82.3\%), and the most common form of health coverage was Medicaid (38.5\%), followed by Medicare $(24.5 \%)$, and no insurance coverage $(22.3 \%)$. Records suggested relatively low completion preventive services; $24.6 \%$ had a flu shot in the past year, $30.9 \%$ of women had a mammogram in the past 2 years, and $38.7 \%$ of age-eligible women had a recent Pap smear.

Tables 3 and 4 show the percentage of patients who had completed a FIT in the subgroups of interest, by intervention group. Although not always statistically significant, we saw a consistent pattern of increased FIT return rates among intervention participants compared to control participants across all subgroups studied, with incidence rate ratios (IRRs) generally ranging from 1.25 to 1.50 . FIT completion in the intervention group ranged from 15 and $25 \%$ for most subgroups, typically three to six percentage points higher than the control group participants. Also shown in Tables 3 and 4 are the relative 
Table 1 Cut-points for dichotomized neighborhood-level moderators

\begin{tabular}{|c|c|}
\hline Moderator & Description and cut-point for dichotomizing \\
\hline Gini Inequality & $\begin{array}{l}\text { The Gini Index, or index of income concentration, is a statistical measure of income inequality ranging from } 0 \text { to } 1 \text {. A } \\
\text { measure of } 1 \text { indicates perfect inequality, i.e., one household having all the income and rest having none. A measure of } 0 \\
\text { indicates perfect equality, i.e., all households having an equal share of income [31]. Dichotomized at 0.4106, the World } \\
\text { Bank estimate of Gini for the USA in } 2013 \text { [32] }\end{array}$ \\
\hline Unemployment rate & $\begin{array}{l}\text { Number of unemployed people as a percentage of the civilian labor force. Dichotomized at } 6.6, \text { the US seasonally adjusted } \\
\text { unemployment rate in January } 2014 \text { [33] }\end{array}$ \\
\hline $\begin{array}{l}\text { Percentage } \\
\text { graduates }\end{array}$ & $\begin{array}{l}\text { ercentage with bachelor's degree or higher. Dichotomized at 41.0, the percentage of US citizens aged 55-64 with tertiary } \\
\text { ducation, } 2014 \text { [34] }\end{array}$ \\
\hline Sopulation density & $\begin{array}{l}\text { Total population divided by the land area measured in square miles. Dichotomized at } 1000 \text { people/square mile, the } \\
\text { definition of a rural tract }\end{array}$ \\
\hline $\begin{array}{l}\text { ledian household } \\
\text { come }\end{array}$ & $\begin{array}{l}\text { 50th percentile household income for the census tract. Dichotomized at 68,426, the median household income in the USA } \\
\text { in 2014, for family households [35] }\end{array}$ \\
\hline Poverty (\%) & $\begin{array}{l}\text { Percentage in census tract living in poverty. Census Bureau uses a set of money income thresholds that vary by family size } \\
\text { and composition to determine who is in poverty. If the total income for a family or unrelated individual falls below the } \\
\text { relevant poverty threshold, then the family (and every individual in it) or unrelated individual is considered in poverty. } \\
\text { Dichotomized at } 17.6 \% \text {, a median split in our study sample }\end{array}$ \\
\hline $\begin{array}{l}\text { ED visits per } 1000 \\
\text { enrollees }\end{array}$ & $\begin{array}{l}\text { Number of emergency department visits per } 1000 \text { Medicaid/Medicare enrollees. Dichotomized at 416, the US average in } \\
2013 \text { [36] }\end{array}$ \\
\hline
\end{tabular}

Abbreviations: ED Emergency department

risks for having completed a FIT (vs. not) in each subgroup and the $P$ value for the treatment"moderator interaction. The only moderator with a statistically significant interaction was race; persons of Asian descent showed a twofold response to the intervention (adjusted incident rate ratio $[\mathrm{aIRR}]=2.06,95 \%$ confidence interval [CI] 1.41 to 3.00). Intervention response was in the more typical range for participants who were White $(\mathrm{aIRR}=$ $1.32,95 \%$ CI 0.99 to 1.76 ) and Black (aIRR $=1.28,95 \%$ CI 0.85 to 1.92). Among persons of Asian descent, 18.9\% in the usual care group completed a FIT, compared with $37.7 \%$ in the intervention group. In contrast, usual care completion rates among White and Black persons were 12.9 and $14.9 \%$, respectively, compared to 15.8 and $20.2 \%$ for the intervention group participants.

Although no other interaction tests were statistically significant, a few other characteristics were statistically significant at $P=0.10$. Specifically, we found larger effects for those with non-obese range BMIs than for participants with $\mathrm{BMI} \geq 30.0$ (aIRR $=1.44$ vs. $1.28, P=0.08$ ), for those without vs. with a visit for diabetes in the past year $($ aIRR $=1.42$ vs. $1.23, P=0.06$ ), and those living in lower poverty vs. higher poverty neighborhoods (aIRR = 1.47 vs. $1.30, P=0.06$ ). However, the preponderance of evidence suggests that intervention effects were fairly consistent across patient subpopulations. We reran the analyses of BMI and the neighborhood-level characteristics that we dichotomized, keeping the moderators as continuous variables (data not shown). None of the interaction terms were statistically significant in these analyses $(P>0.14$ in all cases), supporting the robustness of these findings.

\section{Discussion}

In this population, drawn from safety net clinics in Oregon, Washington, and California serving low-income patients, a wide range of patient subpopulations generally showed fairly comparable responses to the mailed FIT intervention. However, the intervention effect was largest among persons of Asian descent, with a statistically significant incident rate ratio of 2.06 (95\% CI 1.41 to 3.00 ). It is unclear why this subgroup showed large effects, and this result needs replication. One possible explanation we explored was that $77 \%$ of persons of Asian descent in the study population reported that English was not their preferred language, so it was possible that the wordless FIT instructions developed for this trial were particularly helpful for the Asian subpopulation. However, we did not find a greater benefit of the intervention among non-English speakers in general, nor was there a parallel effect in persons of Hispanic descent, who had a similar proportion of non-English speakers (76\%) as the Asian subpopulation.

We found two other trials of mailed FIT interventions that reported on moderators of treatment effect [14, 16], although these trials did not report specifically on differential effects in persons of Asian descent compared to other race/ethnic groups. One of these mailed FIT trials found that the intervention effect was comparable across age, gender, race/ethnicity (Hispanic vs. other), preferred language (English vs. Spanish), and insurance status, but did find a larger treatment effect among persons with no visits during the follow-up period than those with three or more visits, a variable we did not explore [14]. In their study, among persons with no visits during follow- 
Table 2 Baseline individual-level patient characteristics

\begin{tabular}{|c|c|c|c|c|c|c|}
\hline & \multicolumn{4}{|c|}{ Allocation } & \multirow{2}{*}{\multicolumn{2}{|c|}{ All $(n=30,667)$}} \\
\hline & \multicolumn{2}{|c|}{ Usual care $(n=14,904)$} & \multicolumn{2}{|c|}{ Intervention $(n=15,763)$} & & \\
\hline & $N$ & $\%$ & $N$ & $\%$ & $N$ & $\%$ \\
\hline \multicolumn{7}{|c|}{ Age } \\
\hline $50-64$ & 12,249 & 82.2 & 12,749 & 80.9 & 24,998 & 81.5 \\
\hline $65-75$ & 2655 & 17.8 & 3014 & 19.1 & 5669 & 18.5 \\
\hline \multicolumn{7}{|c|}{ Gender } \\
\hline Female & 8381 & 56.2 & 8605 & 54.6 & 16,986 & 55.4 \\
\hline Male & 6523 & 43.8 & 7158 & 45.4 & 13,681 & 44.6 \\
\hline \multicolumn{7}{|c|}{ Race } \\
\hline Asian & 545 & 3.8 & 950 & 6.4 & 1495 & 5.1 \\
\hline Black & 629 & 4.4 & 743 & 5.0 & 1372 & 4.7 \\
\hline Hawaiian/Pacific Islander & 72 & 0.5 & 59 & 0.4 & 131 & 0.4 \\
\hline Native American & 142 & 1.0 & 146 & 1.0 & 288 & 1.0 \\
\hline Other & 9 & 0.1 & 25 & 0.2 & 34 & 0.1 \\
\hline White & 12,886 & 90.2 & 13,010 & 87.1 & 25,896 & 88.6 \\
\hline \multicolumn{7}{|c|}{ Ethnicity } \\
\hline Non-Hispanic & 12,227 & 84.6 & 13,370 & 88.2 & 25,597 & 86.4 \\
\hline Hispanic & 2225 & 15.4 & 1789 & 11.8 & 4014 & 13.6 \\
\hline \multicolumn{7}{|c|}{ Language } \\
\hline English & 12,032 & 81.6 & 12,600 & 81.6 & 24,632 & 81.6 \\
\hline Spanish & 1797 & 12.2 & 1361 & 8.8 & 3158 & 10.5 \\
\hline Other & 920 & 6.2 & 1475 & 9.6 & 2395 & 7.9 \\
\hline \multicolumn{7}{|c|}{ Insurance status } \\
\hline Uninsured & 3494 & 23.8 & 3248 & 20.8 & 6742 & 22.3 \\
\hline Medicaid & 5642 & 38.5 & 6004 & 38.5 & 11,646 & 38.5 \\
\hline Medicare & 3562 & 24.3 & 3868 & 24.8 & 7430 & 24.5 \\
\hline Commercial & 1885 & 12.8 & 2392 & 15.3 & 4277 & 14.1 \\
\hline Other & 88 & 0.6 & 101 & 0.6 & 189 & 0.6 \\
\hline \multicolumn{7}{|c|}{ Federal poverty level } \\
\hline$<100 \%$ & 5870 & 48.8 & 6282 & 53.8 & 12,152 & 51.2 \\
\hline $100-150 \%$ & 2594 & 21.6 & 2529 & 21.7 & 5123 & 21.6 \\
\hline $151-200 \%$ & 1258 & 10.4 & 1126 & 9.6 & 2384 & 10.0 \\
\hline $200 \%+$ & 2316 & 19.2 & 1738 & 14.9 & 4054 & 17.1 \\
\hline \multicolumn{7}{|c|}{ Flu shot in 12 months prior to index date } \\
\hline No & 11,144 & 74.8 & 11,970 & 75.9 & 23,114 & 75.4 \\
\hline Yes & 3760 & 25.2 & 3793 & 24.1 & 7553 & 24.6 \\
\hline \multicolumn{7}{|c|}{ Mammogram in 2 years prior to index date (women, $n=16,986$ ) } \\
\hline No & 5765 & 68.8 & 5976 & 69.4 & 11,741 & 69.1 \\
\hline Yes & 2616 & 31.2 & 2629 & 30.6 & 5245 & 30.9 \\
\hline
\end{tabular}


Table 2 Baseline individual-level patient characteristics (Continued)

\begin{tabular}{|c|c|c|c|c|c|c|}
\hline & \multicolumn{4}{|c|}{ Allocation } & \multirow{2}{*}{\multicolumn{2}{|c|}{ All $(n=30,667)$}} \\
\hline & \multicolumn{2}{|c|}{ Usual care $(n=14,904)$} & \multicolumn{2}{|c|}{ Intervention $(n=15,763)$} & & \\
\hline & $\bar{N}$ & $\%$ & $N$ & $\%$ & $\bar{N}$ & $\%$ \\
\hline \multicolumn{7}{|c|}{ Pap in 3 years prior to index date (women under age $65, n=13,634$ ) } \\
\hline No & 4085 & 60.3 & 4268 & 62.3 & 8353 & 61.3 \\
\hline Yes & 2694 & 39.7 & 2587 & 37.7 & 5281 & 38.7 \\
\hline \multicolumn{7}{|c|}{ Tobacco use } \\
\hline Current & 3892 & 30.0 & 4237 & 30.4 & 8129 & 30.2 \\
\hline Former & 3335 & 25.7 & 3690 & 26.5 & 7025 & 26.1 \\
\hline Never & 5768 & 44.4 & 6018 & 43.2 & 11,786 & 43.8 \\
\hline \multicolumn{7}{|l|}{ BMI } \\
\hline$<18.5$ (underweight) & 190 & 1.4 & 203 & 1.4 & 393 & 1.4 \\
\hline 18.5-25 (normal weight) & 3232 & 23.0 & 3541 & 24.5 & 6773 & 23.8 \\
\hline 25-30 (overweight) & 4456 & 31.7 & 4431 & 30.7 & 8887 & 31.2 \\
\hline$\geq 30$ (obese) & 6164 & 43.9 & 6265 & 43.4 & 12,429 & 43.6 \\
\hline \multicolumn{7}{|c|}{ Charlson score, based on past 12 months } \\
\hline 0 & 7968 & 53.5 & 8648 & 54.9 & 16,616 & 54.2 \\
\hline 1 & 4095 & 27.5 & 4208 & 26.7 & 8303 & 27.1 \\
\hline 2 & 1633 & 11.0 & 1637 & 10.4 & 3270 & 10.7 \\
\hline $3+$ & 1208 & 8.1 & 1270 & 8.1 & 2478 & 8.1 \\
\hline \multicolumn{7}{|c|}{ Visit for chronic pulmonary condition, past 12 months } \\
\hline No & 11,972 & 80.3 & 12,716 & 80.7 & 24,688 & 80.5 \\
\hline Yes & 2932 & 19.7 & 3047 & 19.3 & 5979 & 19.5 \\
\hline \multicolumn{7}{|c|}{ Visit for diabetes, past 12 months } \\
\hline No & 11,590 & 77.8 & 12,430 & 78.9 & 24,020 & 78.3 \\
\hline Yes & 3314 & 22.2 & 3333 & 21.1 & 6647 & 21.7 \\
\hline \multicolumn{7}{|c|}{ Visit for depression, past 12 months } \\
\hline No & 11,080 & 74.7 & 12,083 & 77.0 & 23,163 & 75.9 \\
\hline Yes & 3749 & 25.3 & 3606 & 23.0 & 7355 & 24.1 \\
\hline \multicolumn{7}{|c|}{ Neighborhood ED visits per 1000 Medicaid/Medicare population } \\
\hline$>419$ visits & 13,088 & 88.4 & 15,167 & 96.9 & 28,255 & 92.8 \\
\hline$\leq 419$ visits & 1722 & 11.6 & 485 & 3.1 & 2207 & 7.2 \\
\hline \multicolumn{7}{|c|}{ Neighborhood Gini inequality score } \\
\hline$>0.4106$ & 8197 & 56.9 & 9206 & 60.0 & 17,403 & 58.5 \\
\hline$\leq 0.4106$ & 6216 & 43.1 & 6146 & 40.0 & 12,362 & 41.5 \\
\hline \multicolumn{7}{|c|}{ Neighborhood median household income } \\
\hline$\leq \$ 68,426$ & 13,114 & 91.0 & 14,654 & 95.4 & 27,768 & 93.3 \\
\hline$>\$ 68,426$ & 1299 & 9.0 & 698 & 4.6 & 1997 & 6.7 \\
\hline \multicolumn{7}{|c|}{ Neighborhood percentage college graduates } \\
\hline$\leq 41 \%$ & 11,537 & 80.0 & 12,854 & 83.7 & 24,391 & 81.9 \\
\hline$>41 \%$ & 2876 & 20.0 & 2499 & 16.3 & 5375 & 18.1 \\
\hline \multicolumn{7}{|c|}{ Neighborhood population density per square mile } \\
\hline$\leq 1000$ (rural) & 4423 & 30.7 & 5907 & 38.5 & 10,330 & 34.7 \\
\hline$>1000$ (non-rural) & 9991 & 69.3 & 9446 & 61.5 & 19,437 & 65.3 \\
\hline
\end{tabular}


Table 2 Baseline individual-level patient characteristics (Continued)

\begin{tabular}{|c|c|c|c|c|c|c|}
\hline & \multicolumn{4}{|c|}{ Allocation } & \multirow{2}{*}{\multicolumn{2}{|c|}{ All $(n=30,667)$}} \\
\hline & \multicolumn{2}{|c|}{ Usual care $(n=14,904)$} & \multicolumn{2}{|c|}{ Intervention $(n=15,763)$} & & \\
\hline & $N$ & $\%$ & $N$ & $\%$ & $N$ & $\%$ \\
\hline \multicolumn{7}{|c|}{ Neighborhood poverty (percentage below 100\% FPL) } \\
\hline$>17.6 \%$ & 7384 & 51.2 & 8281 & 53.9 & 15,665 & 52.6 \\
\hline$\leq 17.6 \%$ & 7029 & 48.8 & 7071 & 46.1 & 14,100 & 47.4 \\
\hline \multicolumn{7}{|c|}{ Neighborhood unemployment rate } \\
\hline$>6.6 \%$ & 12,691 & 88.0 & 13,978 & 91.0 & 26,669 & 89.6 \\
\hline$\leq 6.6 \%$ & 1722 & 12.0 & 1375 & 9.0 & 3097 & 10.4 \\
\hline
\end{tabular}

Abbreviations: ED Emergency department, FPL Federal poverty level

up, $3 \%$ of the control group participants and $59 \%$ of the intervention group participants had completed a FIT within 6 months, a 56 percentage point difference between groups. Among those with three or more visits during follow-up, $58 \%$ of the control group and $86 \%$ of the intervention group completed a FIT within 6 months, a 28 percentage point difference. The other trial of mailed FITs that reported effect moderators found no differences in intervention response by gender or race/ ethnicity (comparing non-Hispanic white, black, and Hispanic subgroups) [16].

We adhered to most recommendations outlined by the checklist for the appraisal of moderators and predictors (CHAMP) [37]. First, we examined characteristics related to those that have been shown to be related to CRC screening rates, including demographics, socioeconomic factors, health status, and use of preventive services. The broad factors were selected a priori; however, the specific fields were restricted to those available in the EHR and in the databases of neighborhood-level data use by this study. We used measures taken prior to the start of the interventions, employed statistical interaction testing, and presented results for all moderators examined. In addition, the setting and study population were comparable to the settings and populations in which the mail FIT would be used clinically. Because of the large number of moderators we examined, the relatively small number of participants of Asian descent, and the lack of an effect related to non-English language preference (a construct related to Asian ethnicity), we view the finding of a positive moderating effect in Asian patients as exploratory and in need of replication. We also believe the overall pattern of consistent benefit across a range of patient characteristics in this setting is plausible.

One of the main limitations of this study is related to our reliance on the EHR for capture of moderator variables. Patients in this low-income population may be more mobile than typical, both in terms of where they live and where they receive their healthcare. As such, the neighborhood-level characteristics may not be current for people who struggle with homelessness or insecure housing, and healthcare-related services may be received at non-study clinics. However, low-income patients' mobility is likely primarily between neighborhoods with similar economic profiles, so we believe the information on neighborhood-level characteristics will often remain reasonably similar when patients have moved. However, EHRs are simply not always complete and accurate, so some patients will have been dropped from some analyses due to missing moderator data and some will have been misclassified in the EHR. In addition, some participants may have completed a FIT within a health system that was not covered by the OCHIN collaborative, so they would be misclassified as not completing a FIT.

Another limitation of our study is that we tested a larger number of potential moderators without adjusting our analyses to maintain a type I error rate of $5 \%$. Thus, even though we did find one statistically significant interaction indicating a larger benefit for patients of Asian descent, this finding may be due to chance and not be robust to replication. An additional limitation is that we did not conduct power calculations specifically for the moderator analyses, given the wide range of subgroup sizes, and analyses for some subgroups may be underpowered.

Despite these limitations, our study has a number of important strengths. Our sample included more than 30,000 patients, and so had substantial numbers of patients across a variety of patient subgroups. In addition, these clinics are part of a collaborative that uses a common EHR system, meaning differences in data storage and capture were minimized across the clinics and that data on study participants seen at other clinics under the umbrella EHR provider would be captured. Another very important strength is that this was a pragmatic effectiveness trial, conducted in real-world safety net clinics, using the existing staff and infrastructure. While the overall effect of this intervention was not as large as that seen in some other trials of mailed FITs, the effect was robust across patient subpopulations and was implemented within the constraints of real-world, low-resourced clinics.

The relatively modest effects of an automated FIT mailing intervention were generally consistent across a 
Table 3 FIT completion by individual-level patient characteristics

\begin{tabular}{|c|c|c|c|c|c|c|}
\hline \multirow[t]{2}{*}{ Subgroup variable } & \multirow{2}{*}{$\begin{array}{l}\text { Number of } \\
\text { participants }\end{array}$} & \multirow{2}{*}{$\begin{array}{l}\text { Percentage } \\
\text { completed } \\
\text { FIT }\end{array}$} & \multicolumn{2}{|c|}{ Percentage completed FIT } & \multirow{2}{*}{$\begin{array}{l}\text { Adjusted IRR } \\
(95 \% \mathrm{Cl})\end{array}$} & \multirow{2}{*}{$\begin{array}{l}\text { Interaction } \\
P \text { value }\end{array}$} \\
\hline & & & UC & IG & & \\
\hline \multicolumn{7}{|l|}{ Age } \\
\hline $50-64$ & 24,998 & 15.2 & 13.0 & 17.3 & $1.36(1.02,1.81)$ & 0.58 \\
\hline $65-74$ & 5669 & 16.9 & 14.4 & 19.0 & $1.41(1.03,1.94)$ & \\
\hline \multicolumn{7}{|l|}{ Gender } \\
\hline Female & 16,986 & 16.3 & 14.2 & 18.3 & $1.33(1.00,1.78)$ & 0.33 \\
\hline Male & 13,681 & 14.5 & 12.0 & 16.8 & $1.42(1.05,1.90)$ & \\
\hline \multicolumn{7}{|l|}{ Race } \\
\hline White & 25,896 & 14.4 & 12.9 & 15.8 & $1.32(0.99,1.76)$ & 0.003 \\
\hline Black & 1372 & 17.8 & 14.9 & 20.2 & $1.28(0.85,1.92)$ & \\
\hline Asian & 1495 & 30.8 & 18.9 & 37.7 & $2.06(1.41,3.01)$ & \\
\hline \multicolumn{7}{|l|}{ Hispanic ancestry } \\
\hline Non-Hispanic & 25,597 & 14.8 & 12.5 & 16.8 & $1.39(1.05,1.85)$ & 0.19 \\
\hline Hispanic & 4014 & 21.2 & 18.7 & 24.3 & $1.25(0.91,1.71)$ & \\
\hline \multicolumn{7}{|l|}{ Primary language } \\
\hline English & 24,632 & 13.5 & 11.8 & 15.1 & $1.38(1.04,1.84)$ & 0.89 \\
\hline Non-English & 5553 & 25.5 & 20.2 & 30.6 & $1.40(1.03,1.90)$ & \\
\hline \multicolumn{7}{|l|}{ Insurance status } \\
\hline Uninsured & 6742 & 16.0 & 13.3 & 19.1 & $1.29(0.94,1.78)$ & 0.67 \\
\hline Medicaid & 11,646 & 16.2 & 13.3 & 18.9 & $1.38(1.02,1.88)$ & \\
\hline Medicare & 7430 & 15.5 & 13.8 & 17.1 & $1.34(0.98,1.84)$ & \\
\hline Commercial & 4227 & 13.0 & 12.8 & 13.3 & $1.48(1.05,2.08)$ & \\
\hline \multicolumn{7}{|c|}{ Federal poverty level } \\
\hline$\leq 100 \%$ & 12,152 & 16.8 & 14.4 & 19.0 & $1.29(0.95,1.75)$ & 0.42 \\
\hline$>100-150 \%$ & 5123 & 16.1 & 13.3 & 18.9 & $1.37(0.99,1.89)$ & \\
\hline$>151-200 \%$ & 2384 & 14.9 & 13.0 & 17.1 & $1.27(0.88,1.83)$ & \\
\hline$>=200 \%$ & 4054 & 14.4 & 11.9 & 17.7 & $1.51(1.07,2.11)$ & \\
\hline \multicolumn{7}{|l|}{ Flu shot past year } \\
\hline No & 23,114 & 14.2 & 12.1 & 16.2 & $1.39(1.04,1.86)$ & 0.46 \\
\hline Yes & 7553 & 19.4 & 16.7 & 22.2 & $1.32(0.98,1.79)$ & \\
\hline \multicolumn{7}{|c|}{ Mammogram in past 2 years } \\
\hline No & 11,741 & 14.7 & 12.7 & 16.5 & $1.27(0.96,1.67)$ & 0.18 \\
\hline Yes & 5245 & 20.0 & 17.5 & 22.5 & $1.42(1.06,1.90)$ & \\
\hline \multicolumn{7}{|c|}{ Pap test in last 3 years } \\
\hline No & 8353 & 14.2 & 12.4 & 16.0 & $1.28(0.97,1.70)$ & 0.40 \\
\hline Yes & 5281 & 19.0 & 16.6 & 21.5 & $1.37(1.03,1.84)$ & \\
\hline \multicolumn{7}{|l|}{ Smoking status } \\
\hline Former or never & 18,811 & 17.3 & 14.6 & 19.9 & $1.40(1.04,1.87)$ & 0.16 \\
\hline Current & 8129 & 12.3 & 10.8 & 13.7 & $1.25(0.91,1.72)$ & \\
\hline \multicolumn{7}{|l|}{ Body mass index } \\
\hline$<30.0 \mathrm{~kg} / \mathrm{m}^{2}$ & 16,053 & 15.8 & 13.0 & 18.5 & $1.44(1.07,1.93)$ & 0.08 \\
\hline$\geq 30.0 \mathrm{~kg} / \mathrm{m}^{2}$ & 12,429 & 15.7 & 13.9 & 17.4 & $1.28(0.95,1.72)$ & \\
\hline \multicolumn{7}{|c|}{ Charlson comorbidities } \\
\hline $0-2$ & 28,189 & 15.7 & 13.5 & 17.8 & $1.35(1.01,1.80)$ & 0.16 \\
\hline
\end{tabular}


Table 3 FIT completion by individual-level patient characteristics (Continued)

\begin{tabular}{|c|c|c|c|c|c|c|}
\hline \multirow[t]{2}{*}{ Subgroup variable } & \multirow{2}{*}{$\begin{array}{l}\text { Number of } \\
\text { participants }\end{array}$} & \multirow{2}{*}{$\begin{array}{l}\text { Percentage } \\
\text { completed } \\
\text { FIT }\end{array}$} & \multicolumn{2}{|c|}{ Percentage completed FIT } & \multirow{2}{*}{$\begin{array}{l}\text { Adjusted IRR } \\
(95 \% \mathrm{Cl})\end{array}$} & \multirow{2}{*}{$\begin{array}{l}\text { Interaction } \\
P \text { value }\end{array}$} \\
\hline & & & $\overline{\mathrm{UC}}$ & IG & & \\
\hline$\geq 3$ & 2478 & 13.2 & 10.4 & 15.9 & $1.61(1.11,2.32)$ & \\
\hline \multicolumn{7}{|c|}{ Visits for chronic pulmonary disease } \\
\hline No & 24,688 & 15.7 & 13.4 & 17.8 & $1.35(1.01,1.80)$ & 0.50 \\
\hline Yes & 5979 & 14.7 & 12.3 & 17.0 & $1.42(1.04,1.95)$ & \\
\hline \multicolumn{7}{|l|}{ Visits for diabetes } \\
\hline No & 24,020 & 14.8 & 12.4 & 17.0 & $1.42(1.06,1.89)$ & 0.06 \\
\hline Yes & 6647 & 18.1 & 16.3 & 20.0 & $1.23(0.91,1.67)$ & \\
\hline \multicolumn{7}{|l|}{ Visits for depression } \\
\hline No & 23,163 & 16.1 & 13.7 & 18.3 & $1.37(1.03,1.84)$ & 0.66 \\
\hline Yes & 7355 & 13.9 & 12.1 & 15.8 & $1.33(0.98,1.81)$ & \\
\hline
\end{tabular}

Abbreviations: FIT Fecal immunochemical test, IG Intervention group, IRR Incidence rate ratio, UC Usual care group, CI Confidence interval a Data based on mixed effects Poisson regression analysis controlling for clinic level clustering and adjusting for subgroup variable and, as applicable, age, gender, and health center

Table 4 FIT completion by patients' neighborhood characteristics

\begin{tabular}{|c|c|c|c|c|c|c|}
\hline \multirow[t]{2}{*}{ Subgroup variable } & \multirow{2}{*}{$\begin{array}{l}\text { Number of } \\
\text { participants }\end{array}$} & \multirow{2}{*}{$\begin{array}{l}\text { Percentage } \\
\text { completed } \\
\text { FIT }\end{array}$} & \multicolumn{2}{|c|}{ Percentage completed FIT } & \multirow{2}{*}{$\begin{array}{l}\text { Adjusted IRR } \\
(95 \% \mathrm{Cl})\end{array}$} & \multirow{2}{*}{$\begin{array}{l}\text { Interaction } \\
P \text { value }\end{array}$} \\
\hline & & & $\overline{U C}$ & IG & & \\
\hline \multicolumn{7}{|c|}{ ED visits per 1000 Medicaid/Medicare population } \\
\hline$>419$ visits & 28,255 & 16.1 & 14.2 & 17.8 & $1.34(1.00,1.78)$ & 0.36 \\
\hline$\leq 419$ visits & 2207 & 8.5 & 6.8 & 14.6 & $1.73(0.95,3.14)$ & \\
\hline \multicolumn{7}{|l|}{ Gini Inequality score } \\
\hline$>0.4106$ & 17,403 & 15.2 & 13.1 & 17.1 & $1.37(1.02,1.83)$ & 0.81 \\
\hline$\leq 0.4106$ & 12,362 & 16.1 & 13.5 & 18.8 & $1.39(1.04,1.86)$ & \\
\hline \multicolumn{7}{|c|}{ Median household income } \\
\hline$\leq \$ 68,426$ & 27,768 & 15.6 & 13.2 & 17.7 & $1.37(1.03,1.82)$ & 0.67 \\
\hline$>\$ 68,426$ & 1997 & 15.4 & 14.1 & 17.8 & $1.44(0.99,2.10)$ & \\
\hline \multicolumn{7}{|c|}{ Percentage college graduates } \\
\hline$\leq 41 \%$ & 24,391 & 15.7 & 13.2 & 17.9 & $1.38(1.04,1.84)$ & 0.61 \\
\hline$>41 \%$ & 5375 & 15.1 & 13.6 & 16.8 & $1.33(0.96,1.83)$ & \\
\hline \multicolumn{7}{|c|}{ Population density per square mile } \\
\hline$\leq 1000$ (rural) & 10,330 & 13.4 & 10.6 & 15.5 & $1.45(1.07,1.96)$ & 0.26 \\
\hline$>1000$ (non-rural) & 19,437 & 16.7 & 14.5 & 19.2 & $1.32(0.99,1.78)$ & \\
\hline \multicolumn{7}{|c|}{ Poverty (percentage below 100\% FPL) } \\
\hline$>17.6 \%$ & 15,665 & 16.2 & 13.8 & 18.5 & $1.30(0.97,1.74)$ & 0.06 \\
\hline$\leq 17.6 \%$ & 14,100 & 14.8 & 12.8 & 16.9 & $1.47(1.10,1.98)$ & \\
\hline \multicolumn{7}{|l|}{ Unemployment rate } \\
\hline$>6.6 \%$ & 26,669 & 15.4 & 13.1 & 17.4 & $1.37(1.03,1.82)$ & 0.50 \\
\hline$\leq 6.6 \%$ & 3097 & 17.4 & 14.6 & 20.9 & $1.46(1.04,2.04)$ & \\
\hline
\end{tabular}

Abbreviations: Cl Confidence interval, ED Emergency department, FIT Fecal immunochemical test, FPL Federal poverty level, Gini The Gini Index, or index of neighborhood income concentration, higher number means greater inequality, range 0-1.0, IG Intervention group, IRR Incidence rate ratio, UC Usual care group a Data based on mixed effects Poisson regression analysis controlling for clinic level clustering and adjusting for subgroup variable and, as applicable, age, gender, and health center 
wide range of patient subpopulations, suggesting broad impact that is unlikely to exaggerate existing disparities in CRC screening rates. Patients of Asian descent may be more likely to benefit from the intervention; however, this finding needs to be replicated.

\section{Conclusions}

Response to a mailed FIT intervention was generally consistent across a wide range of individual and neighborhoodlevel patient characteristics, including typically underserved patients and those in low-resource communities.

\section{Abbreviations}

alRR: Adjusted incidence rate ratio; BMI: Body mass index; CMS: Centers for Medicare \& Medicaid Services; CRC: Colorectal cancer; EHR: Electronic health record; FIT: Fecal immunochemical test; GEE: Generalized estimating equation; HMO: Health maintenance organization; IRR: Incidence rate ratio; RR: Risk ratio; STOP CRC: Strategies and Opportunities to Stop Colon Cance in Priority Populations; USPSTF: United States Preventive Services Task Force

\section{Acknowledgements}

Not applicable.

\section{Authors' contributions}

EAO planned the analysis and drafted most of the manuscript. WMV participated in the design of the trial, ongoing trial monitoring, and analysis and interpretation of data. AFP participated in the design of the pragmatic trial and led the implementation of the trial. BBG participated in the trial design and in obtaining funding and interpretation of results, and writing and editing of the manuscript. GDC was the principal investigator of the pragmatic trial and responsible for the design, obtaining funding, the execution of the trial, interpretation of results, and writing and editing of the manuscript. All authors read and approved the final manuscript.

\section{Authors' information}

Not applicable.

\section{Funding}

Research reported in this publication was supported by the National Institutes of Health $(\mathrm{NIH})$ through the National Cancer Institute under Award Number UH3CA188640. Research reported in this publication was supported by the NIH Health Care Systems Research Collaboratory program (UH2AT007782/4UH3CA18864002). The content is solely the responsibility of the authors and does not necessarily represent the official views of the $\mathrm{NIH}$. This paper has not been presented previously.

The study sponsor had no role in study design; collection, analysis, and interpretation of data; writing the report; or the decision to submit the report for publication.

\section{Availability of data and materials}

The deidentified data used during the current study are available from the corresponding author on reasonable request.

\section{Ethics approval and consent to participate}

The study was approved by the Institutional Review Board of Kaiser Permanente Northwest (Protocol \# 4364), with ceding agreements from Group Health Research Institute and OCHIN (formerly Oregon Community Health Information Network). We obtained a waiver of informed consent.

\section{Consent for publication}

Not applicable.

\section{Competing interests}

The authors declare that they have no competing interests.

\section{Author details}

'Kaiser Permanente Center for Health Research, 3800 N. Interstate Avenue, Portland, OR 97227, USA. ${ }^{2}$ Kaiser Permanente Washington Health Research Institute, 1730 Minor Avenue, Suite, Seattle, WA 1600, USA.

Received: 18 July 2019 Accepted: 23 December 2019

Published online: 15 January 2020

\section{References}

1. U.S. Cancer Statistics Working Group. U.S. Cancer Statistics Data Visualizations Tool, based on November 2018 submission data (1999-2016): U.S. Department of Health and Human Services, Centers for Disease Control and Prevention and National Cancer Institute; www.cdc.gov/cancer/dataviz, June 2019.

2. National Vital Statistics System. QuickStats: age-adjusted death rates for top five causes of cancer death, by race/hispanic Ethnicity-United States, 2014. MMWR Morb Mortal Wkly Rep. 2016;65:989.

3. US Preventive Services Task Force, Bibbins-Domingo K, Grossman DC, Curry SJ, Davidson KW, Epling JW Jr, et al. Screening for colorectal cancer: US Preventive Services Task Force recommendation statement. JAMA. 2016; 315(23):2564-75.

4. Maciosek MV, Coffield AB, Edwards NM, Flottemesch TJ, Goodman MJ, Solberg LI. Priorities among effective clinical preventive services: results of a systematic review and analysis. Am J Prev Med. 2006;31(1):52-61.

5. Knudsen AB, Zauber AG, Rutter CM, Naber SK, Doria-Rose VP, Pabiniak C, et al. Estimation of benefits, burden, and harms of colorectal cancer screening strategies: modeling study for the US Preventive Services Task Force. JAMA. 2016;315(23):2595-609.

6. US Department of Health and Human Services Office of Disease Prevention and Health Promotion. Healthy people 2020 topics and objectives: cancer. Washington D.C.: US Department of Health and Human Services; 2017. https://www.healthypeople.gov/2020/topics-objectives/topic/cancer/ objectives.

7. National Colorectal Cancer Roundtable. Tools \& resources $-80 \%$ by 2018 . 2016. http://nccrt.org/tools/80-percent-by-2018/.

8. Centers for Disease Control Prevention. Cancer screening - United States, 2010. MMWR Morb Mortal Wkly Rep. 2012;61(3):41-5.

9. May FP, Yang L, Corona E, Glenn BA, Bastani R. Disparities in colorectal cancer screening in the United States before and after implementation of the Affordable Care Act. Clin Gastroenterol Hepatol. 2019. https://doi.org/10. 1016/j.cgh.2019.09.008

10. Beydoun HA, Beydoun MA. Predictors of colorectal cancer screening behaviors among average-risk older adults in the United States. Cancer Causes Control. 2008;19(4):339-59.

11. Brittain K, Murphy VP. Sociocultural and health correlates related to colorectal cancer screening adherence among urban African Americans. Cancer Nurs. 2015;38(2):118-24.

12. Katz ML, Reiter PL, Young GS, Pennell ML, Tatum CM, Paskett ED. Adherence to multiple cancer screening tests among women living in Appalachia Ohio. Cancer Epidemiol Biomark Prev. 2015;24(10):1489-94.

13. Ricardo-Rodrigues I, Jiménez-García R, Hernández-Barrera V, Carrasco-Garrido $P$, Jiménez-Trujillo I, López-de-Andrés A. Adherence to and predictors of participation in colorectal cancer screening with faecal occult blood testing in Spain, 2009-2011. Eur J Cancer Prev. 2015;24(4):305-12.

14. Baker DW, Brown T, Buchanan DR, Weil J, Balsley K, Ranalli L, et al. Comparative effectiveness of a multifaceted intervention to improve adherence to annual colorectal cancer screening in community health centers: a randomized clinical trial. JAMA Intern Med. 2014;174(8):1235-41.

15. Coronado GD, Golovaty I, Longton G, Levy L, Jimenez R. Effectiveness of a clinic-based colorectal cancer screening promotion program for underserved Hispanics. Cancer. 2011;117(8):1745-54.

16. Gupta S, Halm EA, Rockey DC, Hammons M, Koch M, Carter E, et al. Comparative effectiveness of fecal immunochemical test outreach, colonoscopy outreach, and usual care for boosting colorectal cancer screening among the underserved: a randomized clinical trial. JAMA Intern Med. 2013;173(18):1725-32.

17. Hendren S, Winters P, Humiston S, Idris A, Li SX, Ford P, et al. Randomized, controlled trial of a multimodal intervention to improve cancer screening rates in a safety-net primary care practice. J Gen Intern Med. 2014;29(1):41-9.

18. Jean-Jacques M, Kaleba EO, Gatta JL, Gracia G, Ryan ER, Choucair BN. Program to improve colorectal cancer screening in a low-income, racially 
diverse population: a randomized controlled trial. Ann Fam Med. 2012;10(5): $412-7$.

19. Sequist TD, Franz C, Ayanian JZ. Cost-effectiveness of patient mailings to promote colorectal cancer screening. Med Care. 2010;48(6):553-7.

20. Singal AG, Gupta S, Tiro JA, Skinner CS, McCallister K, Sanders JM, et al. Outreach invitations for FIT and colonoscopy improve colorectal cancer screening rates: a randomized controlled trial in a safety-net health system. Cancer. 2016;122(3):456-63.

21. Singal AG, Gupta S, Skinner CS, Ahn C, Santini NO, Agrawal D, et al. Effect of colonoscopy outreach vs fecal immunochemical test outreach on colorectal cancer screening completion: a randomized clinical trial. JAMA. 2017;318(9): 806-15.

22. Liang PS, Wheat $\mathrm{CL}$, Abhat $\mathrm{A}$, Brenner AT, Fagerlin A, Hayward RA, et al. Adherence to competing strategies for colorectal cancer screening over 3 years. Am J Gastroenterol. 2016:111(1):105-14.

23. Jensen CD, Corley DA, Quinn VP, Doubeni CA, Zauber AG, Lee JK, et al. Fecal immunochemical test program performance over 4 rounds of annual screening: a retrospective cohort study. Ann Intern Med. 2016;164(7):456-63.

24. Schlichting JA, Mengeling MA, Makki NM, Malhotra A, Halfdanarson TR, Klutts JS, et al. Veterans' continued participation in an annual fecal immunochemical test mailing program for colorectal cancer screening. J Am Board Fam Med. 2015;28(4):494-7.

25. Coronado GD, Petrik AF, Vollmer WM, Taplin SH, Keast EM, Fields S, et al. Effectiveness of a mailed colorectal cancer screening outreach program in community health clinics: the STOP CRC cluster randomized clinical trial. JAMA Intern Med. 2018;178(9):1174-81.

26. Coronado GD, Vollmer WM, Petrik A, Taplin SH, Burdick TE, Meenan RT, et al. Strategies and opportunities to STOP colon cancer in priority populations: design of a cluster-randomized pragmatic trial. Contemp Clin Trials. 2014; 38(2):344-9.

27. Vollmer WM, Green BB, Coronado GD. Analytic challenges arising from the STOP CRC trial: pragmatic solutions for pragmatic problems. EGEMS (Wash DC). 2015;3(1):1200,

28. Quan H, Sundararajan V, Halfon P, Fong A, Burnand B, Luthi JC, et al. Coding algorithms for defining comorbidities in ICD-9-CM and ICD-10 administrative data. Med Care. 2005;43(11):1130-9.

29. United States Census Bureau. American Community Survey (ACS). 2017. https://www.census.gov/programs-surveys/acs/.

30. Centers for Medicare \& Medicaid Services. Medicare geographic variation. [updated 07/30/2015, 01/27/2017]. https://www.cms.gov/Research-StatisticsData-and-Systems/Statistics-Trends-and-Reports/Medicare-GeographicVariation/index.html.

31. United States Census Bureau. Census.Gov Glossary. 2017. https://www. census.gov/glossary.

32. World Bank Group. GINI index (World Bank estimate). 2017. http://data worldbank.org/indicator/SI.POV.GINI?locations=US.

33. US Bureau of Labor Statistics. Databases, tables \& calculators by subject. 2018. https://data.bls.gov/timeseries/LNS14000000

34. Organisation for Economic Co-operation and Development (OECD). Population with tertiary education (indicator) 2018. 2018. https://data.oecd. org/eduatt/population-with-tertiary-education.htm\#indicator-chart.

35. US Census Bureau. Income and earnings summary measures by selected characteristics: 2013 and 2014. 2018. https://www2.census.gov/programssurveys/demo/tables/p60/252/table1.pdf.

36. Centers for Disease Control and Prevention (CDC). Emergency department visits. 2018. https://www.cdc.gov/nchs/fastats/emergency-department.htm. [updated May 3, 2017].

37. van Hoorn R, Tummers M, Booth A, Gerhardus A, Rehfuess E, Hind D, et al. The development of CHAMP: a checklist for the appraisal of moderators and predictors. BMC Med Res Methodol. 2017;17(1):173.

\section{Publisher's Note}

Springer Nature remains neutral with regard to jurisdictional claims in published maps and institutional affiliations.

Ready to submit your research? Choose BMC and benefit from:

- fast, convenient online submission

- thorough peer review by experienced researchers in your field

- rapid publication on acceptance

- support for research data, including large and complex data types

- gold Open Access which fosters wider collaboration and increased citations

- maximum visibility for your research: over $100 \mathrm{M}$ website views per year

At BMC, research is always in progress.

Learn more biomedcentral.com/submissions 